strong sense of humanity, have induced me further to declare that the Casarean section should be generally performed as an operation of election; and that craniotomy should be as far as possible abolished, and ought only to be performed as an operation of necessity, except (as already adverted to) in a very few cases.* I am quite aware that many of the opinions I have so urgently stated in the foregoing remarks are at variance with those of the profession generally; yet they have been most conscientiously advocated. They originated from the dictates of humanity, to try to extinguish as far as possible that dreadful expedient-nay, shall I not call it murderous operation?-craniotomy.

Having now fully and without the least reserve put my views into the hands of the profession, I consider I am only doing justice to myself in declaring that I shall not feel called upon to enter into any controversial defence of them.

\section{Giarininal Communitations.}

\author{
ON PUERPERAL FEVER.
}

By T. Sxow BECK, M.D.Lond., F.R.S., Member of the Royal College of Physicians, London.

[Read before the Obstetrical Society of London, February 1st, 1865.]

Is July 1860, I attended Mrs. B. in her first confinement. She had been married about twelve months, was 24 years of age, of rather short stature and good conformation, had always enjoyed good health, and during her pregnancy "never suffered any inconvenience".

On July 24th, she complained of frequent pains in the stomach, which prevented her procuring rest; but without any vaginal discharge. The orifice of the uterus was soft and open, so as to admit the end of the finger.

The following day, the pains were more frequent and of longer duration, became more distressing to her, and were complained of as of a forcing character, chiefly seated in the bottom of the back-the sacrum. The orifice of the uterus was dilated to the size of a five-shilling piece; the membranes entire. There was no vaginal discharge.

The pains continued much the same during the night, but became more decided, retaining their former character, on the afternoon of the 26th. The head descended into the pelvis, and remained stationary for some hours. Ergot of rye and borax were administered without advantage. She became niuch fatigued. The small forceps was introduced, and a small living female child readily extracted, without any perceptible laceration of the perinæum.

Ergot of rye and borax were again given, but without producing any perceptible effect. The placenta was removed by gentle traction on the cord, combined with pressure on the abdomen. Some hæmorrhage followed; and, after it had continued about an hour, I introduced the hand, and found a large, flabby, open uterus, which could not be distinguished through the walls of the abdomen, and which remained inert under the combined influence of the hand internally and pressure externally on the abdomen. Ice was now passed up into the orifice of the uterus, when a slow and languid contraction followed-sufficient to prevent further hæmorr.age, but not sufficient to induce a firm contracted organ. I

* See remarks, page 344 . reluctantly desisted from further efforts in this direction, by reason of the repeated solicitations of her friends.

She passed a good night; and the succeeding daythe 27 th-was so well that she considered "keeping in bed was only a farce".

On the 28th, I was struck with the alteration in her expression, which was anxious and somewhat pinched. The complexion bore a thick muddy hue; she complained of feeling inwardly cold, but had no decided shivering; the pulse was 110 , soft, and otherwise natural ; the skin cool, and moistened with perspiration, which had a peculiar acrid odour. She complained of pain in the left lumbar region, which extended round the abdomen in a line with the crest of the pubic bone, and induced considerable difficulty in turning in bed. The walls of the abdomen were tender in these situations; the lochia not much in amount, and rather offensive; no milk had appeared in the breasts; there were no after-pains; no vomiting; the bowels had not been relieved. A dose of calomel and opium was given, and followed by a gentle saline aperient.

July 29th. A strong, faint, and peculiar offensive odour pervaded the room. The skin was soft, and freely perspiring, which imbued the night-dress with moisture, whilst the exhalation from it appeared to hang about the bed. The expression was anxious and depressed; no pain in the head; mental faculties appeared perfect; no delirium ; feeling of great exhaustion; tongue clean and red; not much thirst; she had occasionally vomited a little froth, slightly tinged with yellow; the bowels were moved several times, the motions being liquid and very offensive; the urine was apparently natural; pulse from 120 to 130 , small, and easily compressed. The pain in the side was relieved, and she could turn in bed with more ease; but a more general soreness existed over the whole abdomen on deep pressure, particularly around the navel and over the hypogastrium. The walls of the abdomen were also tender to gentle pressure. The calomel and opium were continued every four hours, combined with a stimulating diaphoretic mixture, and turpentine fomentations were applied to the abdomen.

July 30th. The odour in the room had nearly disappeared; the offensive odour of the lochia was also gone. She expressed herself as being better. The expression of the face was improved, but still oppressed; and the complexion muddy. The perspiration was much diminished; the pulse from 130 to 140 , weak, and very easily compressed; the tongue clean; no great thirst. She continued to vomit a little froth occasionally; did not complain of pain in the abdomen, unless under firm pressure, when the tenderness was about the same. The walls of the abdomen were more prominent and tympanitic on percussion. The mental faculties were unimpaired.

In the evening, I met Dr. Murphy in consultation, who took a most unfavourable view of the case, although the symptoms continued slightly improved. Camphor and opium, in pills, were directed to be substituted for the former pills; and the other remedies to be continued.

On the following morning-July 31st-she was evidently sinking. In the night, she had vomited some coffee-grounds looking matter upon the pillow, and had slightly wandered in her sleep; was lying on the left side; breathing sighing; could not be roused to consciousness; vomited occasionally on the pillow ; the pulse very rapid, and fluttering.

She gradually sank, and died about noon.

The vomited matters, under the microscope, showed many fat-globules and portions of muscular fibre. The black points were composed of a congeries of 
jointed fibres, resembling the yeast-plant, which, when aggregated together, produced the black colour.

I could not prevail upon the friends to allow an examination of the body, and consequently had not an opportunity for ascertaining whether any, and, if any, what local changes had taken place during this fatal illness, the symptoms and course of which seemed to preclude the idea that it arose from inflammatory action, and appeared to point to the occurrence of some poisonous infection of the whole system. Hence the question arose: By what means could this infection have taken place?

I had attended the lady's family for several years, and herself at different times for slight illnesses; and I thus had an opportunity of knowing that her health was good and her constitution sound. This was, moreover, indicated by the excellent health she enjoyed during the whole of her pregnancy, and the expression of her own feelings the day after the birth of the child, that " keeping in bed was only a farce". The following day, however, evidences of poisoning of the general system were noticed; and this proved of so serious a nature as to cause her death three days after the first symptoms were observed.

The leading feature in the case was the absence of that contractile power in the uterus necessary to effect the expulsion of the child and provide for the safety of the mother after its birth. This was appa. rent at each step of the labour-the languid contraction of the uterus; the inability to increase the force of these contractions by the usual agents; the requirement for the use of the forceps ; the necessity for the removal of the placenta; the hæmorrhage which followed; the existence of a large, flabby, open uterus, when the hand was introduced ; the great difficulty to induce sufficient contraction of the organ to prevent further hæmorrhage; and the impossibility to procure a firm persistent contraction after the cessation of the hæmorrhage. These facts impressed me with the conviction that the poisonous infection of the general system, which showed itself on the second day after delivery, had occurred in consequence of this lax condition of the uterus, which permitted the uterine sinuses to remain pervious; and that this condition arose from the absence of that due contraction of the muscular tissue of the organ which is essential to prevent any fluids from circulating along their canals. From the observation of previous cases, I was assured that the cessation of the hæmorrhage could not be taken as an indication that the amount of contraction had occurred which is necessary to effectually prevent the passage of fluids from the interior of the uterus into the general venous system. But no opportunity occurred for testing the correctness of these opinions, until I met with the following case.

On March 21st, 1864, I was requested to see Sarah H., from whose mother I received the following history.

She was a strong, healthy young woman, 28 years of age; had been married a few years, and was delivered, in her third pregnancy, on the 14th. During her first pregnancy, she was attacked with small-pox, and miscarried with twins. In her second pregnancy, she went the full period, and had again twins, one child being dead, the other living. During her last pregnancy, she was quite well until the night previous to her confinement, when she suffered some pains, but was in "strong pains" for two hours only prior to the birth of the child, which took place before the arrival of the medical attendant. 'The placenta came away about half an hour afterwards, "without any pain".

She had but few after-pains. The lochia were very much, and of a black red colour." All things appeared to progress well until early in the morning of the third day (16th), when she was taken " heartsick, with the head and body full of pain." She vomited some offensive dark coloured matter. The bowels were moved twice, the motions being very copious and very offensive. She had taken castor-oil the same morning. She had no appetite.

Nothing was done for these symptoms, which continued for two days; they then became easier, and "she appeared to be doing nicely". But, early in the morning of the sixth day-the 19th-she awoke saying, "Oh! what shall I do ? I think I am dying ; I never felt such a feeling in my life." The bowels were relieved into the bed; the motions being watery, very offensive, and accompanied with much flatus. She again vomited some offensive dark coloured matter; was very thirsty; had no appetite; " had little dozes, but had never seemed to sleep since her confinement."

She took some Dover's powder, and the sickness appeared to abate. But, about ncon on the seventh day - the 20th-the sickness and purging returned. She also complained much of the pain in the abdomen; and "the perspiration used to stream off the forehead from it." She also complained of "being so weak she did not seem to have strength to move her hands."

The symptoms continued much the same; and I saw her on the morning of the eighth day-the 21st. She was lying on her back, with the head low, the knees drawn up and apart. She complained of a feeling of so much exhaustion and sinking, "as if she would sink through the bed," and "as if she had not power to lift the hand to her head." The expression was anxious; the complexion pale and muddy; the skin cool, or rather cold, with a slight moisture on the surface, but not perspiring; the breathing frequent and short; the pulse about 140, small, soft, and very compressible; the abdomen somewhat distended and tympanitic on percussion. She did not complain of pain ; but, in answer to questions, said she had occasional shooting pains across the upper part of the abdomen. The abdomen was very tender to superficial, as well as to deep and continued pressure. The lips were dry and parched; the tongue large, dry, and dark coloured. There was great and incessant thirst, followed by constant vomiting of what ever was taken ; the vomited matter" was " sometimes quite green." The motions, which were said to be watery and not very offensive, were passed every few minutes into the bed. The urine was also passed into the bed. The lochia said to be sufficiently free, of good colour, and not offensive. There was no pain in the head; and the intellect was quick, clear, and very anxious. She was directed to take some iced brandy and water, with a stimulating astringent mixture.

In the evening, the symptoms were slightly changed. She was talking constantly, yet answered all questions readily and correctly. The skin was warmera slight perspiration on the surface; the eye bright; the face less pale. The vomiting and purging continued unabated. She was lying on the back, frequently moving the arms and legs. In reply to questions, she said she was in no pain. The pulse was very quick and fluttering.

She gradually sank, and died about 2 A.M. on the ninth day-the 22nd.

The body was examined thirty-six hours after death. It was well developed, moderately fat. Some port-wine coloured fluid escaped from the mouth. The abdomen was distended and tympanitic. The uterus could not be felt, nor any tumour through the walls of the abdomen. Some slight green discoloration existed in the left iliac region; also some reddish 
discoloration in lines, marking the course of some veins on the abdomen and thighs. There was considerable fat in the walls of the abdomen. The small and large intestines were much distended with flatus ; there was no unpleasant odour. The omentum was considerably injected; the small intestines were somewhat injected at their contiguous edges. About two pints of opaque, dirty, yellowish, and oily looking serum were found in the cavity of the abdomen, in which floated numerous shreds of loose friable lymph. The whole of the peritoneum was slightly injected, and the surface covered with a thin layer of soft friable recent lymph, rather thicker in some places. The mucous membrane of the small and large intestines was pale; they were much distended with air. There was a small amount of fæces in the descending colon. The fimbriated extremities of the Fallopian tubes were of dark, almost black colour, from great injection. The uterus was large, spongy to the feel, round, and even, occupying the hollow of the sacrum; its surface was somewhat injected. The liver was apparently healthy. The kidneys were also healthy; their capsules were thin and transparent. The veins of the pelvis were not distended; and, on dividing them, the blood was fluid, thin, and of a brownish red colour. No coagula were observed.

The uterus was removed for further examination. It was round, pear-shaped, even on the surface, soft and rather flabby to the touch. It measured five inches across the fundus, five inches and three-fourths in length. The walls of the body were one inch and one-tenth thick, eight-tenths of an inch at the neck, six-tenths at the fundus, and at one part not more than four-tenths of an inch. The cavity was large, three inches and three-fourths at the fundus, five and a half inches longitudinally; and was every where covered with a dark brownish red mucous discharge, which was readily removed, leaving a smooth, uniform, and slightly red surface beneath, studded over with those small depressions, about one-tenth of an inch in diameter, which are caused by the decussation of the internal layer of muscular fibres. The situation of the placenta was marked by an oval and less red patch on the anterior surface of the body. The neck of the uterus was of a deep, approaching to a black colour, which appeared to arise from blood effused into the tissues. The upper portion of the vagina was of similar character, but not so deep. The line of separation between the mucous membrane of the uterus and that of the vagina was distinctly marked. The secretion on the surface of the uterus was of a mucous character, and loaded with round ovate, and in some instances spindle-shaped bodies (elementary corpuscles), comparatively few blood-discs, some mucus-corpuscles, many fat-globules, and a few columnar epithelium-cells.

When placed under water, the inner surface of the uterus was seen to be every where covered with a soft membrane, from which numerous shreds proceeded, and floated in the water. This membrane consisted chiefly of the round or ovate bodies found in the mucous secretion (elementary corpuscles), amorphous connective tissue, and contractile fibre-cells. The portion marking the former attachment of the placenta was thicker, and appeared as if a thin layer of that body was left adhering to the uterus. It contained several (what appeared to be) small coagula of blood, and consisted of elements similar to those already noticed, with some fibrous tissue.

At this part of the uterine surface, numerous open orifices were observed, which, when pressed, emitted a minute portion of their fluid blood, and which led directly to sinuses of considerable size beneath. Air blown into the uterine and spermatic veins escaped out of those orifices, and ascended through the water; and water injected into the same veins readily escaped into the uterine cavity.

There was not any appearance of inflammatory product in any part of the uterus. The veins were empty ; their walls not injected; their surface smooth and shining. The lining membrane of the sinuses was clear and shining, and the connecting tissue beneath healthy. The lymphatics were also empty and transparent. The muscular tissue was undergoing the usual amount of fatty degeneration, but otherwise appeared unchanged from that of healthy tissue.

In this case, the labour appears to have been natural, and the placenta was expelled without any assistance. No hæmorrhage occurred; whilst the abundant flow of the lochia and the blackened colour of the discharge were the only symptoms to indicate that the uterus was not fully contracted. Everything appeared to progress favourably until the third day after the birth of the child, when symptoms indicative of general poisoning first arose. These were not marked, and appear to have remained stationary, if not somewhat diminished, during the two following days ; but, on the morning of the sixth day, they recurred with increased severity, and continued gradually to increase until death took place, early in the morning of the ninth day after the delivery. In the examination after death, extensive peritonitis, of a low type, was observed, with a copious effusion of serum, and of that soft friable lymph which characterises these cases. But, beyond this, all the tissues of the uterus were found, after careful and even minute examination with the microscope, to be perfectly healthy. No appearance of inflammatory action was any where observed; and the only condition differing from that of health was the soft flabby state of the uterus-its full size; and the important circumstance, that the uterine sinuses remained so open as to allow air blown into, and water injected into, the uterine and spermatic veins, to traverse these canals, and to escape by the open orifice on the inner surface of the organ. I think it is, then, fair to assume that, where these vessels are pervious to admit fluids to pass in a direction contrary to the course of the blood, these fluids may pass in the direction of the current of the circulation. It is even probable that the blood flowing along the large veins would produce an exhaustive effect, and thus facilitate the entrance of fluids into the uterine sinuses.

So far, then, as any deductions may be justified from these cases, they appear to show that:

1. The phenomena of puerperal fever may be produced by the introduction of poisonous fluids into the general system.

2. The uterine sinuses remaining pervious to the flow of fluids, would afford a means by which this poisonous fluid or fluids would enter the system.

3. The pervious condition of the sinuses remained, in consequence of an absence of that firm and persistent contraction of the uterus after childbirth which appears necessary to effectually close these canals and prevent all circulation of fluids along them.

4. The secretion from the interior of the uterus was probably sufficient, when mixed with the blood, to induce the effects observed; and it would further follow that:

5. The various phenomena observed in puerperal fever may arise from this cause, modified infinitely by many incidental states; and the various inflammatory actions and products observed in the course of the disease would not be the essential parts of the disease, but morbid phenomena which occurred during the course of it. 
6. The primary, though not the only object, in the prevention of these attacks of puerperal fever, will then be to procure a firm, complete, and persistent contraction of the uterus after the birth of the child, and thus effectually to shut off all circulation within the vessels of this organ.

But it remains to be seen how far these conclusions accord with the results of previous observers.

\section{[To be continued.]}

\section{CONGENITAL LUXATION OF FEMUR: NECROPSY.}

By Dr. Berend, Director of the Orthopædic Establishment at Berlin.

The necropsy of a boy, 6 years old, suffering from congenital luxation of the femur, showed the following particulars. The acetabulum was found in its normal situation, reduced to one-third of its proper circumference; and the articular surface was almost flat, instead of concave, apparently through deficiency of the surrounding capsular ligament. The head of the femur rested in a new articulation on the outer surface of the ilium, behind and a little above the acetabulum. This new articular surface was limited posteriorly by a semi-circular bony wall which would have formed a complete acetabular cavity, if the bony ring had been a little higher and extended entirely around. The head of the bone, partially atrophied but not at all destroyed by ulceration, was turned upon its axis in such manner that the trochanter major pointed directly forwards (ante-

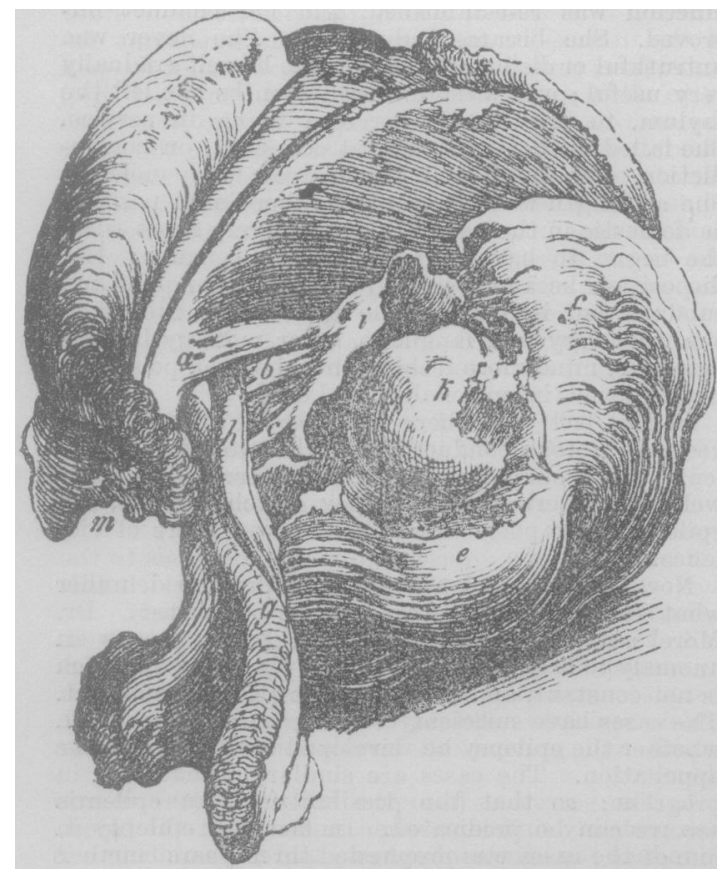

$a$, Pyriformis muscle; $b$, Gemellus superior; $c$, Gemellus inferior; $d$, Obturator internus ; $e$, Quadratus femoris; $f$, Glutæus major reflected; $g$, Glutæus minor reflected; $h$, Sciatic nerve; $i$, Capsular ligament; $k$, Head of the femur; $i$, Ilium; nerve; $i$, Capsular

riorly) ; a small portion of the original capsular ligament, arising from the anterior portion of the acetabular ring and extending over that cavity, was in- serted into the edge of the sacro-ischiatic notch, with no attachment to the neck of the femur, but a narrow insertion in the head of the bone itself. The rotator muscles (pyriformis, gemelli, and obturator internus) were quite as abnormally situated, being inserted into the false capsular ligament itself and not into the trochanter. Moreover, they were found to be atrophied; and, apparently as a secondary effect, to have undergone fatty degeneration. Finally, the situation of the quadratus femoris was also abnormal as to its usual insertion. This last circumstance was due to the rotation of the femur: the muscle was extended over the surface of the bone, and appeared to be rolled upon it.

\section{ILLUSTRATIONS OF THE DIFFERENT FORMS OF INSANITY.}

By W. H. O. SANkeY, M.D.Lond., Proprietor of Sandywell Park Private Asylum; Lecturer on Mental Disease in University College, London; late Medical Superintendent of the Female Department, Hanwell Asylum.

[Continued from page 291.]

OF the varieties in form of mental disease: some affect chiefly the moral and intellectual faculties, and the motor are involved in a secondary manner. Two forms, however, are more immediately connected with the motor functions ; viz., general paresis, which was described in the last paper; and epileptic mania, which remains to be illustrated.

In all cases of mental disease, there is some disturbance of the motility, as shewn in restless activity, or in torpidity of movement. In general paresis, the motor functions give a prominent feature to the disease. But they form the primary affection in that form called epileptic mania.

Cases of epileptic mania form some of the most formidable and trying with which the physician has to deal. The disease presents itself in two forms, according to $\mathrm{my}$ experience. In one, the maniacal symptoms appear to be superadded to an ordinary case of epilepsy; being, as it were, an extension of the morbid processes from the motor to the moral and intellectual faculties. In these cases, the violence is at one period very great and peculiar; being more totally uncontrollable and furious than is met with in cases of ordinary mania. The patient makes a sudden and unprovoked attack on the nearest bystander perhaps, and cannot be soothed or temporised with, as in an excitement of passion. Some of these patients direct their violence towards themselves, and will butt with their head against a wall, or will bite and tear their own flesh. It is usually on account of these outbreaks of violence that the asylum is sought; and many such cases were admitted into Hanwell during my term of office there. In all these patients, the maniacal violence gradually subsided after admission. The violence, or maniacal furor, in most of these cases, preceded each epileptic seizure; in some, however, it followed; and, in others, the fits and the violence took place together.

The second variety of epileptic mania is met with in two forms; viz., 1, with the epilepsy undeveloped; and 2, with epileptic attacks developed. The former has been described and named by my friend, Dr. Morel of Rouen, as epilepsia larvalis. (Traité des Mal. Men., p. 480.)

It appears to be somewhat an anomaly to name an affection epilepsy, in which no epileptic seizure has yet occurred; and one cannot exactly affirm that the one condition is a premonitory or previous stage of the other; for certainly the second state is possibly, 431 